\title{
Application of Additive Technologies in the Production of Aircraft Engine Parts
}

\author{
Anton V. Agapovichev ${ }^{1}$, Andrei V. Balaykin ${ }^{1}$, Vitally G. Smelov ${ }^{1} \&$ Andrey V. Agapovichev ${ }^{1}$ \\ ${ }^{1}$ Samara State Aerospace University, Samara, Russia \\ Correspondence: Anton V. Agapovichev, Samara State Aerospace University, Samara, Russia.
}

Received: January 3, 2014

Accepted: February 3, $2014 \quad$ Online Published: January 11, 2015

doi:10.5539/mas.v9n4p151

URL: http://dx.doi.org/10.5539/mas.v9n4p151

\begin{abstract}
The use of rapid prototyping technologies provides a unique opportunity of cost-effective methods of investment casting to create new industrial products, of particular importance is the cost and speed of production. Development and research of rapid prototyping technologies have allowed a new level of optimization and introduction of new technologies into various industries. The essence of investment casting is that to get the castings use a single, accurate non-split, ceramic shell molds, which are produced on single models using liquid molding compounds. Before pouring the melt, a model shape is destroyed by melting, burning, dissolving, or evaporation. To remove residues of the model and hardening, mold is heated to high temperatures. Calcination form before its filling virtually eliminates gas formation and improves occupancy melt. At the stage of pilot production, which is characterized by frequent changes in design, the problem of the rapid production of cast components becomes crucial. This is mainly due to the complexity of manufacturing foundry equipment. The aim of this work is to identify opportunities and evaluate accuracy of the casting size during investment casting using rapid prototyping technology. The work was conducted with the use of cross-cutting design in CAM / CAD / CAE systems. The work has been verified according to the adequacy of the virtual simulation of the casting formation process in the casting simulation ProCAST, in comparison with those obtained castings. The study showed that the use of rapid prototyping technologies with investment casting can significantly reduce the time for making castings, reduce production costs and improve the accuracy of the casting size.
\end{abstract}

Keywords: employment additive technology, rapid prototyping, silicone mold, wax model, ceramic form

\section{Introduction}

To date, Foundry is one of the main techniques for metal products and preparations for various industries. The advantage of foundry is the fact that it allows to receivework pieces and parts of different alloys of almost any configuration with any entity roughness, different masses, and other various properties.

The main direction of improvement for any production is modernization of the well-known and creation of the new technological processes to reduce material consumption, decrease labor costs and energy, improve working conditions, eliminate or reduce harmful effects on the environment. All this ultimately increases the efficiency of production and products (Dimitrov, D. et al., 2006).

Traditionally, the process of parts machining at most of engineering companies in the industry take about $70-80 \%$ of the total time of their manufacture (Cheah et al., 2005).

To save material and time resources for the design, development and manufacturing of products, promising is the use of new technological processes, both in procuring, as well as in the main production (Onuh \& Yusuf, 1999).

Rapid prototyping technology is widespread in certain industries (Griffiths, 1993), such as automotive, aerospace, medical and others. Research and development of rapid prototyping technologies allowed moving to the new level of optimization and the introduction of new processes in different areas of the industry (Hopkinsonet al., 2006).

The article describes a method of manufacturing aircraft parts by investment casting (IC) using rapid prototyping method. IC method takes a lot of time because of technological difficulties associated with obtaining accurate master models and casting wax models to create complex shapes with high geometric precision (Sun, C. et al., 2014). 
At the same time the IC method is one of the most efficient ones in creating complex shapes of metal (Vaeziet al., 2011), and in some cases - the only possible method of casting, for example, when items have undercuts, thin walls or complex configuration. Speeding up the process of investment casting should improve the efficiency of the details manufacturing process. However, this cannot prevent the reduction of the geometric accuracy of the obtained product (Chicaet al., 2013).

Additive Technology Laboratory is a division of the collective use center "Interdepartmental Training Research and Production Center CAM-technology" (CUC "CAM- technology").

Equipment installed in the laboratory produces prototypes of products, the master - model, high-precision products, according to the available 3D models in the shortest time with high quality characteristics. Objet 3D Printer 350 by Israeli company EDEN has a field for printing products $350 \mathrm{~mm}$ by $350 \mathrm{~mm}$ and $200 \mathrm{~mm}$ deep, with printing accuracy of up to 16 microns. The printer may grow a model of 10 different materials, different in physical properties.

The main difference between rapid prototyping technologies from the standard approach is as follows (Yan et al., 2009):

- the cost and time of preparation is much lower than the standard approach (about 5 times);

- the number of cycles of tooling usage is much lower than in the standard approach.

The aim of the article is to present the experience of practical use of additive technologies, namely of rapid prototyping and pouring wax in silicone masters for the production of gas turbine parts.

This approach is particularly useful in cases when it is necessary to quickly produce a wax model or plastic products with complex shape and high quality (Balyakin, A.V. et al., 2012).

The manufacturing process of part blanks comprises the following steps (Zybanov, S.V. et al., 2009):

- digitizing parts or surface modeling, including the construction of a 3D model in the CAD system;

- process simulation of casting billet in the CAE system;

- growing master model of photopolymer plastic products on a 3D printer;

- manufacturing master models for the mold of silicone;

- pouring wax into a silicone mold;

- coating wax models by ceramic shell and removing wax;

- pouring metal into the ceramic shell;

- removing ceramic shell and cut the runner feed system;

- control of the resulting preform detail.

\section{Materials and Methods}

To obtain master models or prototypes of products, it is necessary to build its three-dimensional model in the CAD system. To build 3D models of parts, there were used a solid modeling system volumetric by Russian developer CAD / CAM / CAPP ADEM VX (Figure 1) and a system of automated design, manufacturing and engineering analysis (CAD / CAM / CAE) NX (Figure 2) from Siemens PLM Software.

After constructing a 3D model of a part we built a 3D work piece model (Figure 3), by deleting some holes, adding the machining allowance, if necessary, technological gains and fillings, and forming runner feed system.

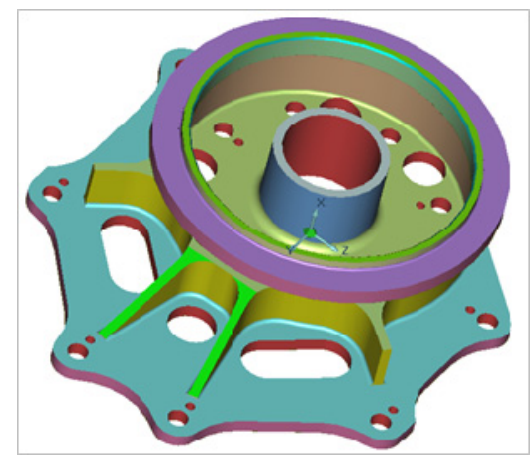

Figure 1. 3D part model, made in the CAD / CAM / CAPP system ADEM VX 


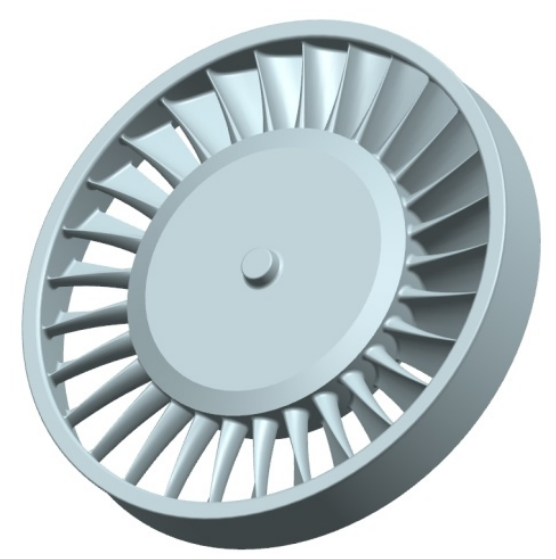

Figure 2. 3D part model, made in the CAD / CAM /CAE system NX

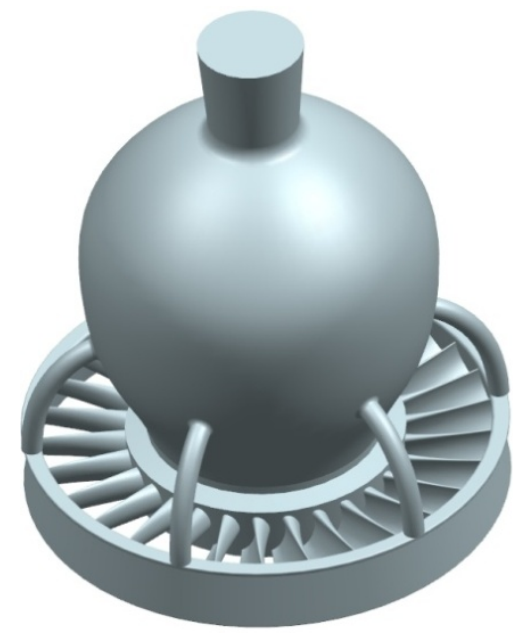

Figure 3. 3D model of the work piece

At this stage, the future preform of detail is enlarged considering any shrinkage of the material. Required coefficient of shrinkage was determined according to the following formulas:

where, $\alpha$ - coefficient of metal shrinkage, $\beta$ - shrinkage factor of wax $\mathrm{L}_{\mathrm{v}}-$ overall size of the stencil, $\mathrm{L}_{1}-$ overall size of the molded part, $\mathrm{L}_{\mathrm{m}}$ - overall size of the photopolymer model. Considering the small values of the coefficients $\alpha$ and $\beta$, the summand can be considered negligible. Thus, the correction factor of the photopolymer master model is the sum of the coefficients of shrinkage of wax and metal.In case of using heat-resistant alloy, and the wax model, $b=1,5$ and $c=1$.The resulting formula does not take into account the shrinkage of ceramic forms, which constitute about $1 \%$. Thus, an extending-shrinkage ratio is equal to $3.5 \%$.

Before growing the master model, manufacturing silicone molds and pouring wax, a virtual simulation of the forming billet was performed in CAE system of foundry simulation ProCast.

ProCAST is a foundry simulation system, providing a joint solution of temperature, hydrodynamic and deformation problems with unique opportunities of studying all possible processes of casting of foundry alloys. An additional advantage of ProCAST is that it is possible to calculate the stress, microstructure and more exotic casting processes of the model (Vdovin, R.A., 2012).

Some critical conditions, such as cold form, low filling speed or low casting temperature may cause problems with completing the form ( $\mathrm{Li}, \mathrm{H}$ et al., 2014). ProCAST predicts when and where there may be filling or cold shuts, porosity, shrinkage voids, air bubbles. All the necessary design changes can be verified with minimal costs, directly on the computer (Bassoli, E. et al., 2007).

In order to optimize a runner feed system (LPS), CAE modeling system holds a virtual fill sprue tree (Figure 4) 
and, as a result, minimizes the appearance of brake in casting billets, abandons test fills and receives satisfactory parts in minimal time (Futas \& Pribulova, 2013).

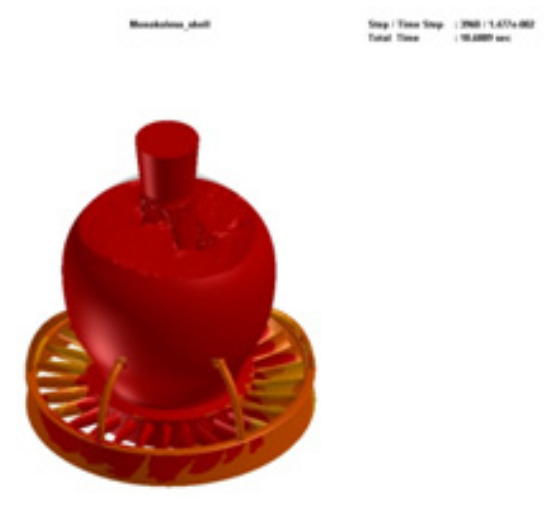

ProCAST

Figure 4. Modeling the process of filling the shell mold and the temperature distribution of the melt in CAE system ProCast

A master model (Figure 5), made on a 3D printer, was used to prepare flexible forms of silicone compound. Products are tested for zero defects (scratches and chips). Before using the geometry, each master model was tested at the gauging machine.

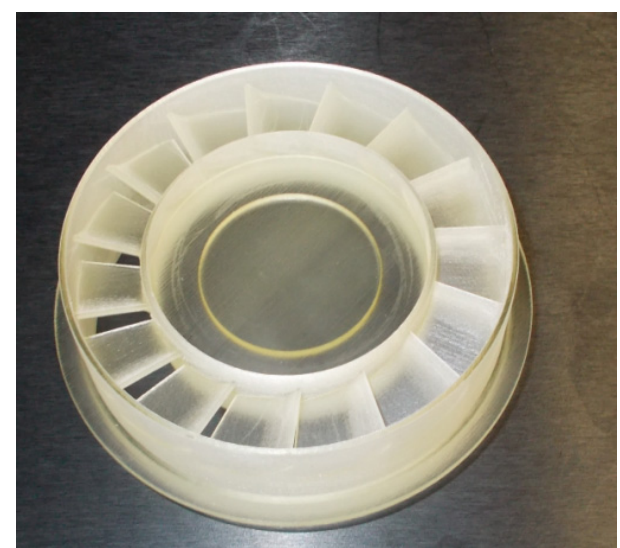

Figure 5. Master model obtainedby3D printer Objet 350

The use of silicone allows to receive wax models of any complexity: undercut, with complex parting surface, with different inserts. Reproduction is possible for complex forms and smallest details.

The principle of making wax models by casting technology in flexible forms lies in absolutely exact copying of the master model. Simple form is manufactured by filling polymerizable silicone around the model. Silicone mold is made by pouring prepared prototype of product grown on the 3D-printer (Gill, S.S. \& M. Kaplas, 2009).

We have developed a technique for designing technological processes of silicone moldsmanufacturing (Figure 6) using different methods of forming surfaces of the connector.

Degassing of the silicone before pouring into the mold eliminates surface defects and porosity of structure.

Maximum dimensions of manufactured parts (castings) constitute $800 \times 500 \times 400 \mathrm{~mm}$, the maximum weight of parts is up to $4-5 \mathrm{~kg}$. 


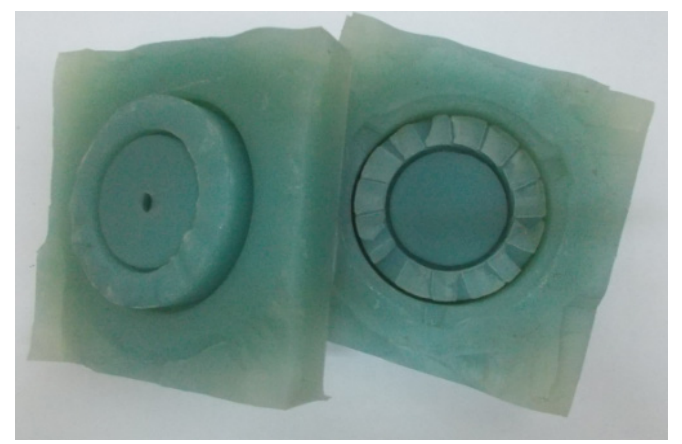

Figure 6. Silicone molds

Degassing of the silicone before pouring into the mold eliminates surface defects and porosity of structure.

Maximum dimensions of manufactured parts (castings) constitute $800 \times 500 \times 400 \mathrm{~mm}$, the maximum weight of parts is up to $4-5 \mathrm{~kg}$.

Silicone molds can be used to produce casting models for a small number of parts (about 100 pieces).

Casting under vacuum provides elastic forms of prototypes and small lots of plastic parts and lost wax models of any complexity without making traditional technological equipment.

Through the use of a wide range of materials castable copies can be elastic tough, heat-resistant ultraviolet-resistant transparent and / or of different colors, as well as wax. For this we use special molding bicomponent polymers cast in elastic forms in vacuum. After curing, the physical and mechanical properties of these polymers are identical to traditional thermoplastic materials (ABS, PS, PP, etc.). Bicomponent compositions imitating the properties of different elastomers are also available. To obtain wax models special modeling waxes are used.

The use of modern materials, as well as water-based binder, sand, zirconium allows to create ceramic molds of high quality and achieve the minimum allowance and high surface quality of the detail (Jones and Yuan, 2003).

To prevent the ceramic shell from cracking during the subsequent process of heating-cooling-firing, several experiments to produce optimal results have been carried out.

The first layer of "ceramics" is applied and then dried in air for 3-4 hours, then the second layer is applied. Ceramic shell is applied until we get 12-16 layers (Figure 7).

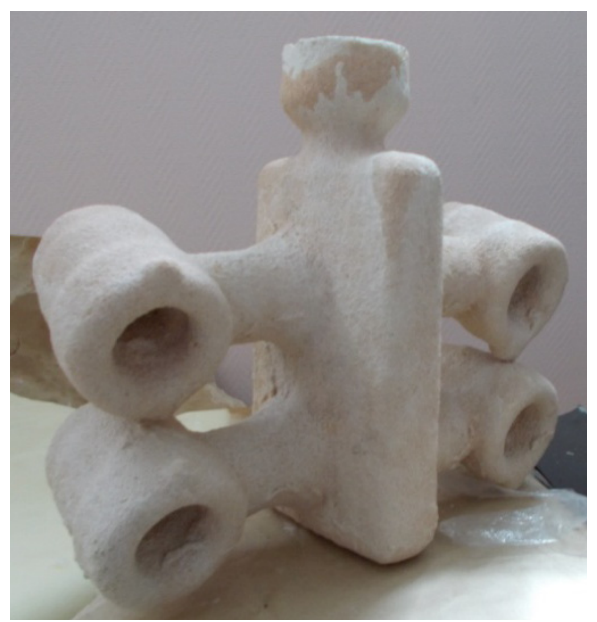

Figure 7. Ceramic form

At a temperature of $100-120^{\circ} \mathrm{C}$ wax gating system and the model itself are lost from the ceramic shells. Ceramic shell should be warmed to a temperature of melting wax as soon as possible. In order to accelerate warming up a preheated furnace is used. A ceramic shell is left for 2 hours at $950^{\circ} \mathrm{C}$, then the oven door is slightly opened for 20-30 minutes in order to add a sufficient amount of air. Then it incubated for another 2 hours for complete 
melting of the model (Kaplas, M. \& R. Singh, 2008).

Thereafter, the shell is cooled and the slag, a quantity of which can be present in the shell, is removed. The casing is then calcined again, the metal is poured into it (Figure 8).

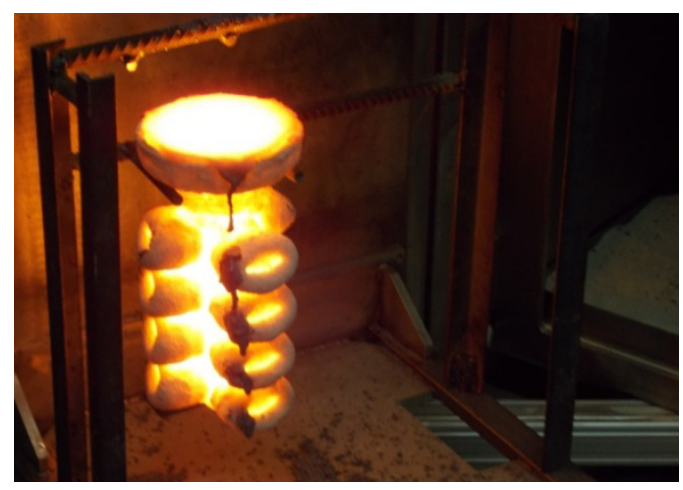

Figure 8. Filling ceramic mold

Melting and pouring of the metal were produced in an induction oven in vacuum, which keeps the metal from unwanted impurities.After the destruction of the ceramic shell and cleaning of ceramic remnants, the molded product is obtained (Figure 9).

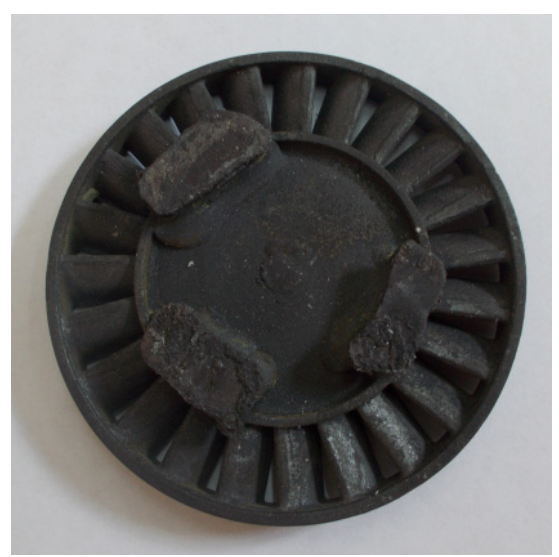

Figure 9. The finished product

\section{Results}

Determined is the quality of the casting size, surface roughness, structure, mechanical and physical properties of the metal, as well as the presence or absence in the casting of internal and external defects, such as voids, blockages, cracks, etc.

Technology for producing castings affects their quality and, consequently, defines the principles that should be followed in the design.

The advantages of the method of investment casting using additive techniques may be implemented, if the casting for the production is manufacturable by this method. A tech is the design of the molded part, in which you can make a casting that meets the requirements of accuracy, surface roughness, physical and mechanical properties and structure of the metal with the least expenditure of time and money (Ivanov V.N. et al., 1984)

Dimensional accuracy is evaluated by the actual deviations from the nominal size of the casting. In our case, the dimensional accuracy of the resulting casting was tested by co-ordinate measuring machine. All dimensions are made in tolerance. Measured above-obtained casting resultsare soot-related with technical requirements.

Currently, a simulation of casting processes in shell molds of five parts is provided.

The check of the adequacy of obtained calculation results of casting processes by comparing them with actual 
fabricated parts has been implemented.

The analysis has shown that the microstructure represents extractional replicy. The matrix represents austenite with sites various etching capacity. In dark sites a very small particles of $\mathrm{TiC}$ are visible, wich were formed firstly. Large particles form mainly chains.

The basis of reliability of virtual simulation is the realistic calculation by CAE system of physical properties of materials and engineering process that defines them.

Studies have made it possible to analyze the above mentioned methods in terms of increasing the rate of production of products and accuracy of the obtained castings.

\section{Discussion}

Modern economic conditions have led to considerable reduction of volumes of production both in aviation branch as a whole, and in aviation angine building in particular that has caused appreciable changes of technology and the manufacture organisation. Besides, an exit domestic aviation of engine building on the world markets and participation in the international cooperation of creation of aviation technics necessity of rapprochement, or harmonisation of processes of creation of aviation technics, including technologies, with the foreign technics. Complex application of information technology at creation of foreign aviation technics demands transition to them and domestic aviation engine building. (Balyakin, A.V. et al., 2012).

Machining processes in the production of aerospace components Profile require considerable time.

The main direction of improvement of any production is modernization of the well-known and creation of the new technological processes to reduce material consumption, reduce labor costs and energy, improve the conditions of labor, eliminate or reduce harmful effects on the environment and, ultimately, improve production efficiency and quality production.

To save material and time resources for the design, development and manufacture of parts, promising is the use of rapid prototyping technology, etc. (Pham, D.T. \& R.S. Gault, 1998 ).

It is essential to optimise foundry processes and to save time and material resources the computer analysis of foundry processes allows. At a design stage of technology of moulding (before manufacturing moulding) allows to minimise possible miscalculations and the errors inevitably arising in the course of working out to lower financial and time expenses to raise efficiency, competitiveness, quality and reliability of developed production (Vdovin, R.A., 2012.).

\section{Conclusion}

The essence of investment casting is that of obtaining of castings used a single, accurate non-split, ceramic shell molds produced on single models using liquid molding compounds. Before pouring, the melt model is removed from the mold by melting, burning, dissolving, or evaporation. To remove residues of the model and hardening, mold is heated to high temperatures. Calcination form before its filling virtually eliminates mix gas-generation value and improves occupancy melt.

Used in the investment casting molds at a sufficiently high fire resistance and chemical inertness of the material allow the production of castings with surface high quality and low surface roughness.

Lack of a connector shape, the use of models for manufacturing materials is to disassemble the form for their removal, high refractory material forms, heating it to a high temperature before pouring and others. Improved occupancy is capable of producing castings of complex configuration, as close as possible or appropriate configuration of the finished part from virtually all known alloys.

Lost Wax Casting is a multi-operational process. Operations for the manufacture and assembly of models, application of slurry on the model and others are quite complex and time-consuming, making it difficult to automate the process. The process consists of a series of long-running operations, defining performance: layering and drying of the layers of the shell mold model, calcination form.

Due to the large number of operations, technological factors affecting the size of the cavity and thus casting can decrease the accuracy of the castings.

The quality of castings produced in this manner depends significantly on the stability properties of the starting materials for making models, suspensions, as well as the stability of process conditions.

This article describes the technology of parts production by investment casting using rapid prototyping technology, which allows a short time to work out details of varying difficulty by the production technology, to produce thin-walled parts of complex shape without usage of sophisticated equipment (Singh, R. \& J.P. Singh, 
2009).

By means of use of additive technologies it was possible to reduce essentially term of manufacturing of a detail, to cut down expenses on equipment manufacturing, to raise production efficiency. It, finally, has led to reduction of time of an exit of a finished article on the market.

A further area of research is related to the identification of the relationship between the properties derived from parts of their production technology that will allow giving further details of the desired properties.

\section{Acknowledgement}

This work was financially supported by the Government of the Russian Federation (Ministry of Education and Science of the Russian Federation) by decree number 218 of 09/04/2010 (theme code 2013-218-04-4777).

\section{References}

Balyakin, A. V., Smelov, V. G., \& Chempinsky, L. A. (2012). Additive technology application details of combustion. Vestnik of the Samara State Aerospace University, 3-2(34), 47-52. ISSN: 1998-6629.

Bassoli, E., Gatto, A., Iuliano, L., \& Violante, M. G. (2007). 3D printing technique applied to rapid casting. Rapid Prototyping Journal, 13, 148-155. http://dx.doi.org/10.1108/13552540710750898

Cheah, C. M., Chua, C. K., Lee, C. W., Feng, C., \& Totong, K. (2005). Rapid prototyping and tooling techniques: A review of applications for rapid investment casting. International Journal of Advanced Manufacturing Technology, 25, 308-320. http://dx.doi.org/10.1007/s00170-003-1840-6

Chica, E., Agudelo, S., \& Sierra, N. (2013). Lost wax casting process of the runner of a propeller turbine for small hydroelectric power plants. Renewable Energy, 60, 739-745. http://dx.doi.org/10.1016/j.renene.2013.06.030(60)

Dimitrov, D., Schreve, K., \& De Beer, N. (2006). Advances in three dimensional printing - State of the art and future perspectives. Rapid Prototyping Journal, 12(3), 136-147. http://dx.doi.org/10.1108/13552540610670717

Futas, P., \& Pribulova, A. (2013). Computer simulation of casting produced by investment casting technology. International Multidisciplinary Scientific GeoConference Surveying Geology and Mining Ecology Management, SGEM, 1, 29-36. http://dx.doi.org/10.5593/SGEM2013/BB2.V1/S07.004

Gill, S. S., \& Kaplas, M. (2009). Comparative study of 3D printing technologies for rapid casting of aluminium alloy. Materials and Manufacturing Processes, 24(12), 1405-1411. http://dx.doi.org/10.1080/10426910902997571

Griffiths, M. (1993). Rapid prototyping options shrink development costs. Modern Plastics, 70, 45-47. ISSN: 00268275.

Hopkinson, N., Hague, R. J., \& Dickens, P. M. (2006). Rapid Manufacturing: An Industrial Revolution for the Digital Age. John Wiley \& Sons, Ltd, ISBN: 0470016132; 978-047001613-8, pp: 1-285.

Ivanov, V. N., Kazennov, S. A., \& Kurchman, B. S., et al. (1984). Investment Casting (3rd ed.). Moscow, M: Mashinostroenie.

Jones, S., \& Yuan, C. (2003). Advances in shell moulding for investment casting. Journal of Materials Processing Technology, 135, 258-265. http://dx.doi.org/10.1016/S0924-0136(02)00907-X

Kaplas, M., \& Singh, R. (2008). Experimental investigations for reducing wall thickness in zinc shell casting using three-dimensional printing. Proceedings of the Institution of Mechanical Engineers, Part C: Journal of Mechanical Engineering Science, 222(12), 2427-2431. http://dx.doi.org/10.1243/09544062JMES1131

Li, H., Chandrashekhara, K., Komaragiri, S., Lekakh, S. N., \& Richards, V. L. (2014). Crack prediction using nonlinear finite element analysis during pattern removal in investment casting process. Journal of Materials Processing Technology, 7, 1418-1426. http://dx.doi.org/10.1016/j.jmatprotec.2014.02.010

Onuh, S. O., \& Yusuf, Y. Y. (1999). Rapid prototyping technology: Applications and benefits for rapid product development. Journal of Intelligent Manufacturing, 10, 301-311. ISSN: 09565515(20).

Pham, D. T., \& Gault, R. S. (1998). A comparison of rapid prototyping technologies. International Journal of Machine Tools and Manufacture, 38(10-11), 1257-1287. ISSN: 08906955.

Singh, R., \& Singh, J. P. (2009). Comparison of rapid casting solutions for lead and brass alloys using three-dimensional printing. Proceedings of the Institution of Mechanical Engineers, Part C: Journal of 
Mechanical Engineering Science, 223(9), 2117-2123. http://dx.doi.org/10.1243/09544062JMES1387

Sun, C., Shang, W., Zhou, J., \& Li, B. (2014). Numerical simulation and process optimization of superalloy integral precision investment casting diffuser. Cailiao Kexue yu Gongyi/Material Science and Technology, 22, 100-104. ISSN: 10050299.

Vaezi, M., Safaeian, D., \& Shakeri, M. (2011). Integration of reverse engineering and rapid technologies for rapid investment casting of gas turbine blades: A comparison between applicable rapid technologies for blade rapid investment casting was conducted and reported in this paper. Virtual and Physical Prototyping, 6, 225-239. http://dx.doi.org/10.1080/17452759.2011.631173

Vdovin, R. A. (2012). 3D virtual simulation and casting process optimization of part GTE "swirler of II duct" with using computer technologies. Vestnik of the Samara State Aerospace University, 3-3(34), 115-120. ISSN: 1998-6629.

Yan, Y., Li, S., Zhang, R., Lin, F., Wu, R., Lu, Q., Xiong, Z., \& Wang, X. (2009). Rapid Prototyping and Manufacturing Technology: Principle, Representative Technics, Applications, and Development Trends. Tsinghua Science and Technology, 14, 1-12. http://dx.doi.org/10.1016/S1007-0214(09)70001-X

Zybanov, S. V., Smelov, V. G., Pronichev, N. D., \& Surkov, O. S. (2009). Increase of effIciency of technological preparation of manufacture on the basis of through use of the information technology. Vestnik of the Samara State Aerospace University, 3-3, 127-131. ISSN: 1998-662.

\section{Copyrights}

Copyright for this article is retained by the author(s), with first publication rights granted to the journal.

This is an open-access article distributed under the terms and conditions of the Creative Commons Attribution license (http://creativecommons.org/licenses/by/3.0/). 